\title{
The Historical and Genetic Model as a Method of Structuring and Choice of the Settlement Development Strategy
}

\author{
Lyubov Kubetskaia ${ }^{1, *}$
}

\author{
${ }^{1}$ Central Institute for Research and Design of Ministry of Construction and Housing and Communal Services of the \\ Russian Federation, Moscow, Russia \\ *Corresponding author. Email: kubeckayal@mail.ru
}

\begin{abstract}
This paper looks at the genesis and evolution of the urban fabric in order to understand the model of the settlement structure, consisting of different historical parts and layers. Several genetic models were considered, those tied to their geographical factors, administrative, religious, and cultural roles of the city. Analyzing the settlement evolution enables for construction of the model as a composition of its genetic parts, as a basis for genetic zoning to be used for planning and building regulations, to enable a knowledgeable approach to future development plans.
\end{abstract}

Keywords: Urban structure evolution, genesis, genetic development code, settlement systems, historical-

genetic model

\section{INTRODUCTION}

The urban structure is a complex system, developing in the course of centuries. It has its forms of development, its inherent rules, and its genetic code [1]. The urban structure bears imprints of certain stages of evolution and centuries-old historical development [2]. As a rule, within an urban fabric, there are zones of different formation periods as well as varying architectural qualities. Genetic parts are well already evident in the urban structure and morphology in the 16th century [3]. These include kremlin, posad, sloboda, the remaining buildings and walls of monasteries, markets hall and arcades, squares, "fascinating with the originality of their forms, imagery, and essence" [4]. Mokeev suggests it appropriate to consider them as monuments of "urban planning". His research is dedicated to the restoration of the original town plan as a whole as it was before the 18th century. He identified a characteristic typology of the ancient planning systems of several cities, including Moscow and Pskov [5].

This study aims to construct a historical genetic model, containing a consistently established evolutionary system, representing cultural heritage, preservation of which serves as a guarantor of the integrity, value zoning, and guidance for any future urban development.
In order to build a historical genetic model of the settlement, the parameters and components, listed below, must be analyzed.

The study relies on the following methodology:

- Consistent research of the evolution and stages of the development

- Comparison of the periods of the development of the religious dominants and public complexes;

- Marking the changes in the urban morphology and the city plan;

- Analysis of the dynamics in the territorial development, historical boundaries and the shape of the city

- Graphical metric analysis of the positioning of the church buildings, social and religious centers;

- Topological analysis of the site (the relationship between the genetic zones and the natural elements)

- Analysis of the genetic connections at the scale of the historical system of settlement;

- Qualitative analysis of the planning and building development (stylistic, homogeneity, etc.)

- Morphological analysis of the plan; 
- Analysis of the degree of the preservation of the planning structure as well as the buildings

As a result of the conducted research, we obtain knowledge about the regulations of the formation of the urban planning structure, on the basis of which the model is built. The identified genetic parts have their value characteristics, which serve as the basis for the genetic zoning and the forecasting future development of the territory.

The order of the mutual arrangement of the genetic parts is influenced by the natural and town-planning conditions, as well as by the historical settlement system, which characteristic features are reflected in the town-planning structure. At the present stage, territorial planning requires the introduction of new methods or the methodology for studying the urban planning structure. It is formulated as a sequence of fundamental points and procedures, described and used by Russian experts, presenting new methodological research, developed by the authors of the article. The works of $\mathrm{L}$. M. Tverskoi, I. V. Makovetskii, V. A. Lavrov, T. F. Savarenskaya, V. A. Bondarenko, D. O. Shvidkovsky, G. Y. Mokeev, V. P. Orphinskiy, Y. S. Ushakov are used as the theoretical basis of our historical genetic studies. Some valuable findings and points from the works by the authors such as A. S, Schenkov, M. P. Kudryavtsev, L. D. Mazur, I. S. Krasovsky, E. A.Shevchenko, as well as the results of practical experience of V. N. Viborniy, A. B. Trenin, E. E. Solovieva, and N. A. Potapova are considered in the methodological and criterial apparatus representing architectural and urban schools of Tatarstan, Nizhny Novgorod, Samara, Sverdlovsk, etc.

Many scholars paid out the utmost attention to the regional approach, which calls for the safeguarding of large (territorial) natural and cultural landscapes and even provinces in areas inhabited by ethnic communities, for example, in the highlands of Georgia [6]. The study takes into account methodologically important requirements for conducting urban morphological research, for example, conducted by the French scholars S. Salat and L. Bourdic, as well as studies of the historical value of the territory, contained in the works of other renowned European scientists, such as V. Gregotty [7].

\section{THE EXAMINATION OF YAROSLAVL AND Pereslavl-ZALESSKY}

As evidenced by the studies, the town-planning structure bears traces of the stages of evolution and the centuries-old historical development, characterized by diverse use of the territory and includes zones of different temporal formation and architectural qualities. In the ancient Russian city in the early stages, the core grad was formed, a fortified settlement that included the kremlin, a detinets, a fortress, posad and a central market. The ancient genetic parts are clearly depicted in the layout of Yaroslavl: the Kremlin (1) on the Strelka, two monasteries Spassky (2) and Troitsky (3), posad (4), surrounded by a defence wall (5) ("Fig. 1") [8]

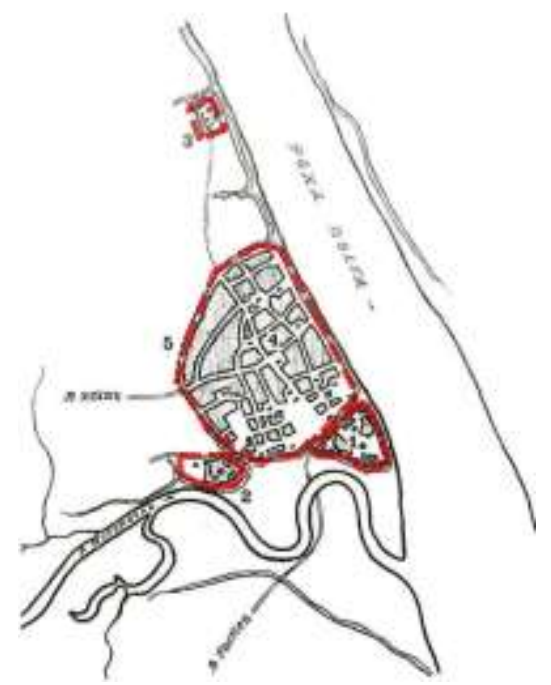

Fig. 1. The City of Yaroslavl. The plan of the 13th century [8].

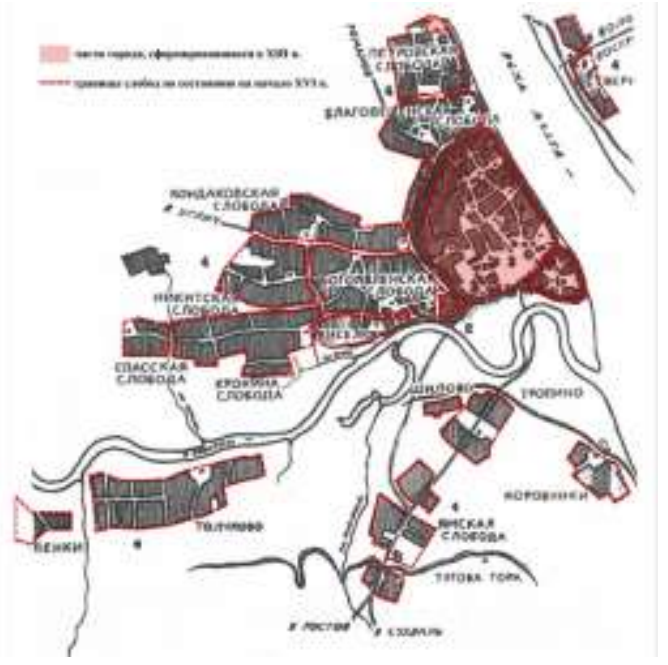

Fig. 2. The City of Yaroslavl. The plan at the beginning of the 16th century. 


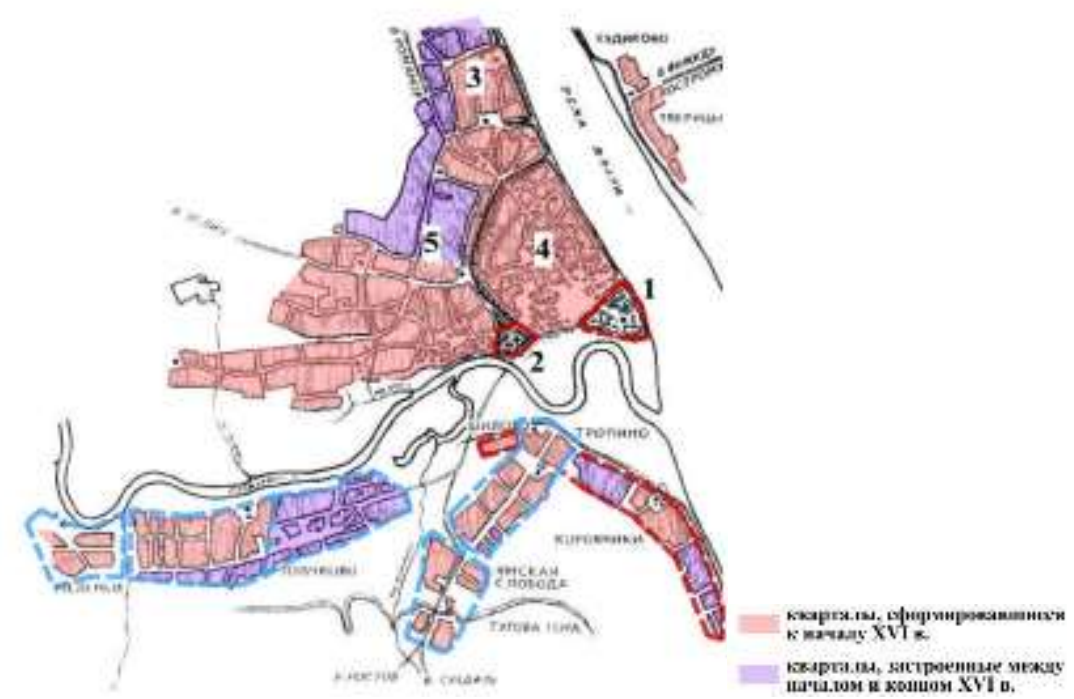

Fig. 3. The map of the territory of the city at the end of the 16 th $\mathrm{c}$. and the beginning of the 16th c. The scheme by F. Marov [8]

a. 1 - Kremlin, 2 - Spassky monastery. 3 - Trinity monastery, 4 - Posad, 5- the defense wall belt, Slobodas: Epiphany, Annunciation, Kondakovskaya, Spasskaya, Krokhina, Kislukha, Tropino, Shilovo,

The plan at the beginning of the 16th century illustrates the growth of the settlement along the river Kotorosl and along the main roads to Rostov to the south direction, to Uglich to the west, and Romanov to the north ("Fig. 2") [9]. The newly developed territories presented linear stretches. A comparative analysis of the plans from the beginning and the end of the 16th century shows that during this period the filling out of these areas took place ("Fig. 3"). In other words, the principal model of the development of the townplanning structure of the right-bank part of Yaroslavl schematically represented a concentric, radial-belted form. There is also a subsequent cyclical pattern: first, there are focuses of development along the main directions, which are later replaced by phases of infilling of the vacant spaces between them. Therefore, the genetic code was conceived in the early stages. But later, during the years of industrialization, the predominantly linear development and territorial expansion to the north was intended. Consequently, the length of the city today exceeds $30 \mathrm{~km}$ along the river Volga.

The study of the evolution of the urban structure has revealed some common typical forms of territorial growth: finger-shaped, belted, edge (fringe), linear axial, polycentric, and others [10]. The emergence of a settlement, the phase of its conception, is an important stage both in the evolution and in the genesis of its structure. It was precisely then that the basic qualities and characteristics of its structure, layout, and composition have been laid.

As we can see, the peculiarity of the town-planning structure of Pereslavl is that the first settlement on the
Yamskaya, Tugova, Melenki, Tveritsy, Hudakova, Pushkar.

Lake Plescheevo was the original fortified settlement founded by Vyatichi in the 8th century, when the city of Kleschin was abandoned. It was resumed by Yury Dolgoruky at a new location, $3 \mathrm{~km}$ to the south, exactly on the main road leading to Rostov on the north-east, and later in the south-west direction towards Moscow. The plan represented a two-part structure to the northeast of the ovoid shape close to the new Kremlin with its posad. The southern part of the plan formed around the Goritsky, Fedorovsky, and Trotsky-Danilov monasteries, as cores, the gaps between which were later filled by the expanding development. This twopart town-planning structure of the city has remained to this day, disconnected from its historical origin Kleshchin. It was no longer the purposes of defense, but the economic and political ties that have become priorities ("Fig. 3"). Without understanding this model of the development it is impossible to build a perspective one.

The overall development followed a linear principle along the Moscow-Rostov state communication axis. The foundation of the town-planning structure was held by the monasteries, of which there were sixteen in Pereslavl in total ("Fig 5"). The ancient part of the city, the Gorodishe, essentially the ancient town of Kleschin, its origin, was "protected" by the Nikitsky monastery and remained memorial and uninhabited. Why did Yury Dolgoruky begin to lay out a new location for the Kremlin? This is because the importance of the Moscow-Rostov road was higher for the development of the city than the remote location of the settlement, close to the lake. Moreover, the base settlement network at the state level was tied to the roads. This principle has been known since the days of ancient 
Rome. The Romans built fortresses with strategic goals in mind, namely along the rivers and military roads, to cover the operational lines. The strategic development of the city cannot ignore this genetic code of the stringing parts of the town planning structure onto a national-level artery. Even in case of an automobile bypass of the city being added, the city's historical exposition will remain deployed along the MoscowRostov route.

The city, as a complex system, is capable of selforganization, organic development, following its internal genetic code. Evolution as a method of studying the urban structure enables us to reveal this process. At the same time, there are differences in the patterns of the initial and subsequent stages of urban development. A process becomes evident in the early stages of the formation, the progress from a multitude to a grouped order of elements, and later towards a unified, dominating (within this multitude) organism. Next, the development of the settlement itself follows, then we see the formation structured according to the ideology like grad - posad - marketplace (a), as well as a grad - posad with a marketplace in the middle (b). There are examples of the coexistence of two posads (Vladimir) and even four (Tver). There are other genetic types of purely posad-based structures, such as Tikhvin, Kholmogory.

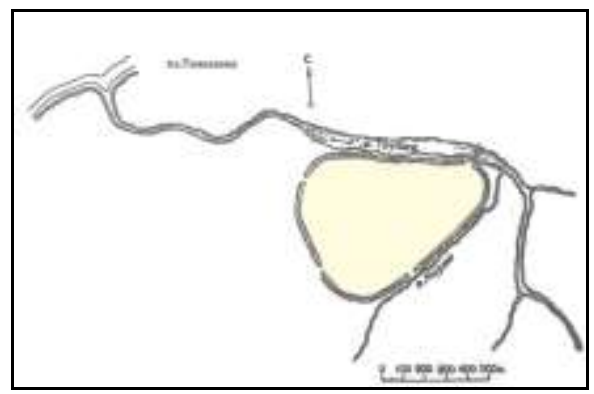

Fig. 4. Pereslavl-Zalessky. The position of the fortress (Kremlin) of the 12th century, built by Yuri Dolgoruky [11]
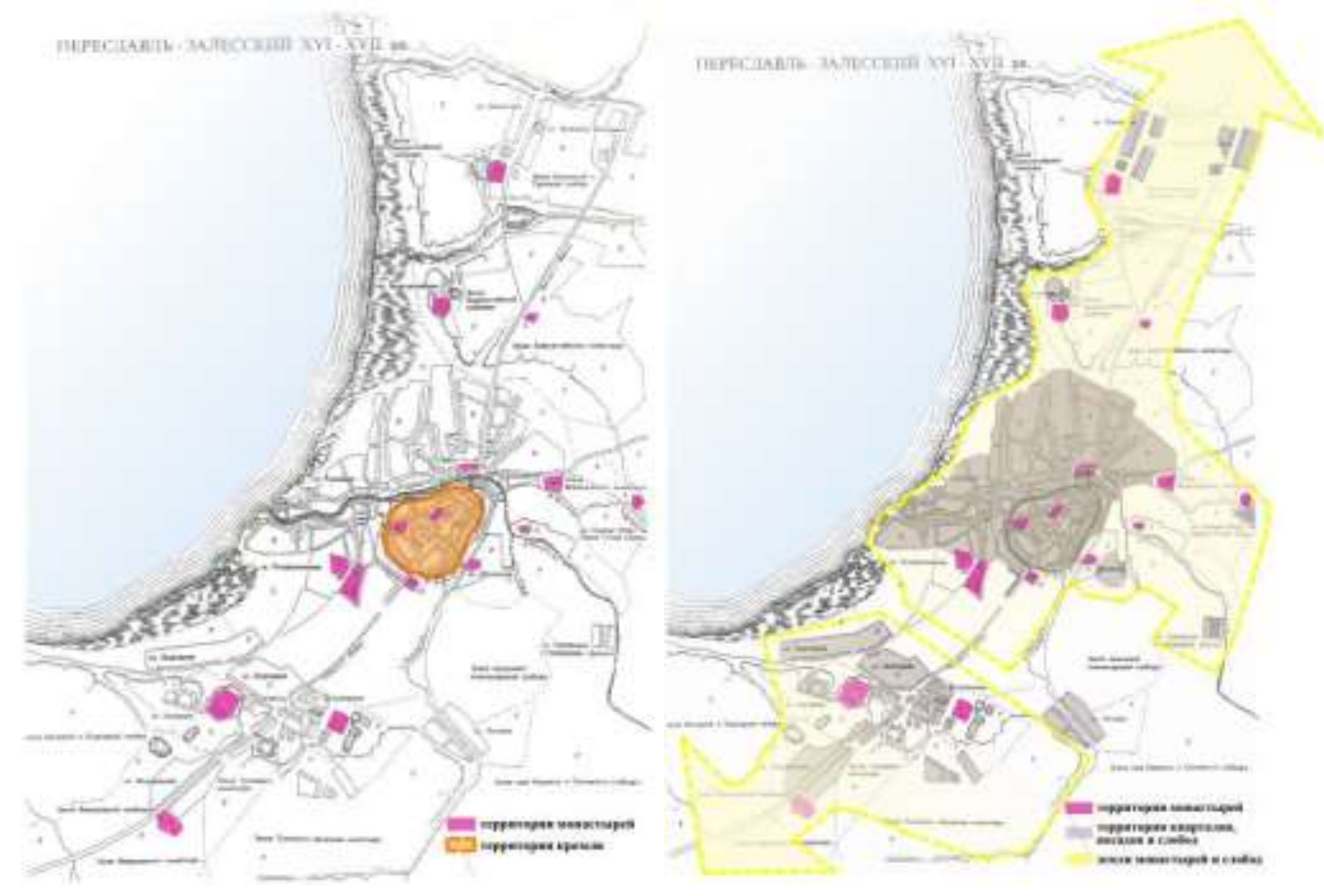

Fig. 5. The city of Pereslavl-Zalessky.

\section{NIZHNY NOVGOROD}

The analysis of the early stages of the settlement confirms that it is during this period the historical genetic interconnections and principal elements of the structure have been established as the foundation, which would determine the subsequent interposition of the new parts.
Has the shape and configuration of the Kremlin had any influence on the structure of the town plan and in what way? A comparative analysis of the earliest known 16th-century plan of the Kremlin against the plan of 1769 testifies to the similarity of the configurations. The geometric shape of the new Kremlin almost completely repeats the shape of the original Kremlin, but with an increase to the territory ("Fig. 6") [12]. 

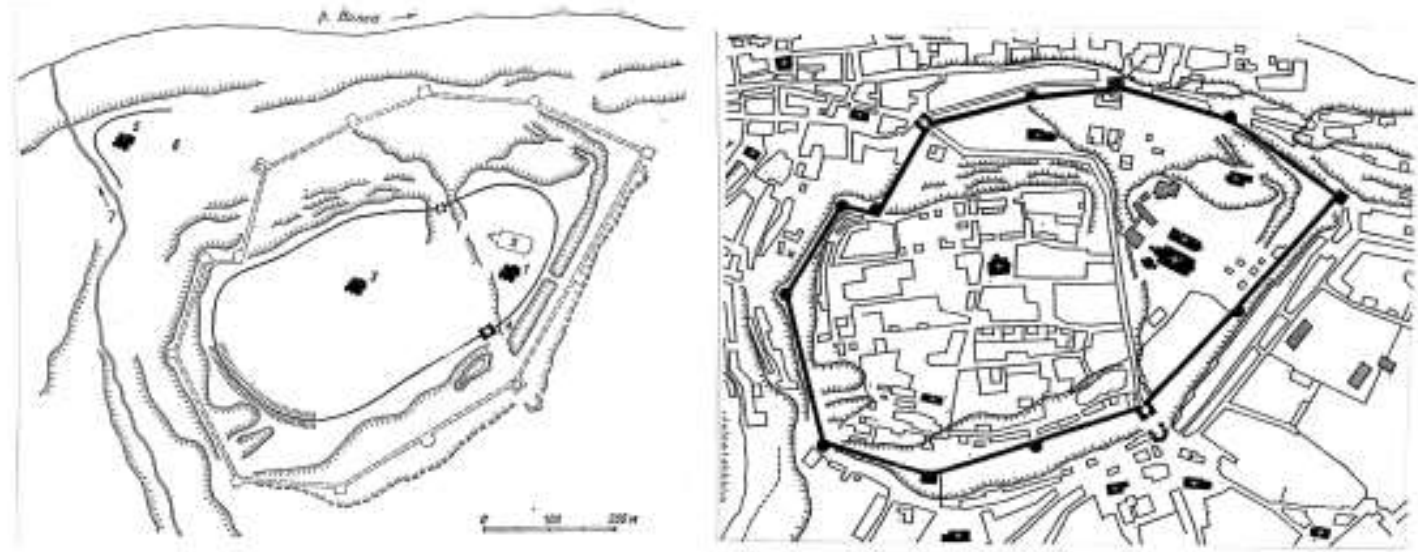

Fig. 6. The city of Nizhny Novgorod.

Thus, the form of the Kremlin of Nizhny Novgorod has become the main core of the town planning structure, determining the characteristic configuration, which was reflected within the boundaries of the Upper and the New Posad. The same pattern can be traced when comparing the plans of the 14th and 16th centuries. We can see the similarity of the configurations of the borders of the territory of the New Posad, formed in the 16th century, with the old, corresponding to the territory of the Upper Posad of the 14th century [14] ("Fig .7").

On the plan of the 14th century, we see the new lower part, in which the newly formed marketplace, Zaryadye, Zachatievsky monastery, Slobodi (settlements), and six new churches are visible. One can see the similarity of the boundaries, like the new Posad repeating the outline of the old Posad, but with an increase to the territory, and the incremented upper ridge of the boundary ("Fig. 8"). The analysis of the subsequent stages of the middle of the 19th century shows the manifestation of the embedded concentric principle in the genetic code of the development of the city.

On the plan of the 14th century we see the configuration of the Kremlin located on the high hill, 

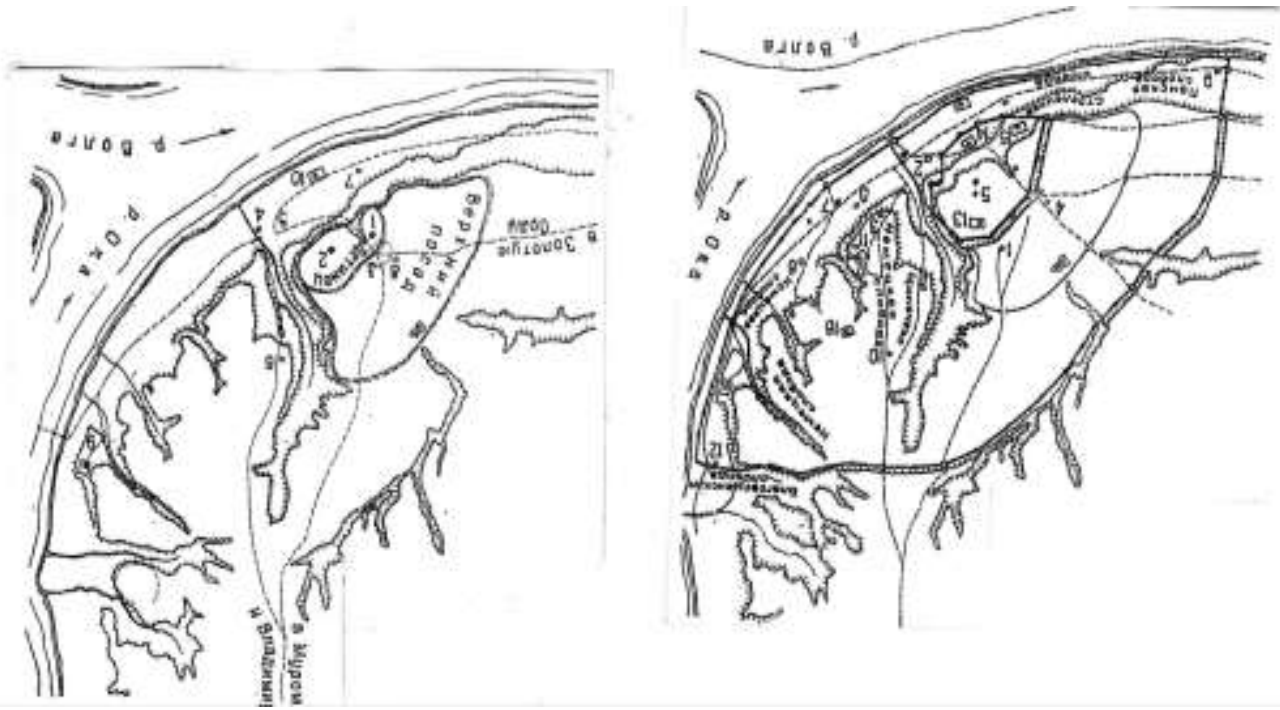

Fig. 7. The comparison of plans 14th-15th centuries on the left (a) - Nizhny Novgorod - the grand knyaz's capital. Reconstruction of the plan of the city of the 14th century, On the right (b) - Nizhny Novgorod - the defense point of the Moscow State XV. 1-1 Spassky Cathedral, 1352; 2- The Cathedral of the Archangel, 1359; 3 - Dmitrovskaya Tower, 1372; 4 - Church of St. Nicholas (na torgu), 1371; 5- bargaining; 6- Church of MyrrhBearers, mid-14th century; 7- Church of Boris and Gleb, 14th century; 8- The Church of Dmitry Solunsky, middle of the 14th century; monasteries: 9Blagoveshchensky, 1370; 10- Zachatievsky, 1355.

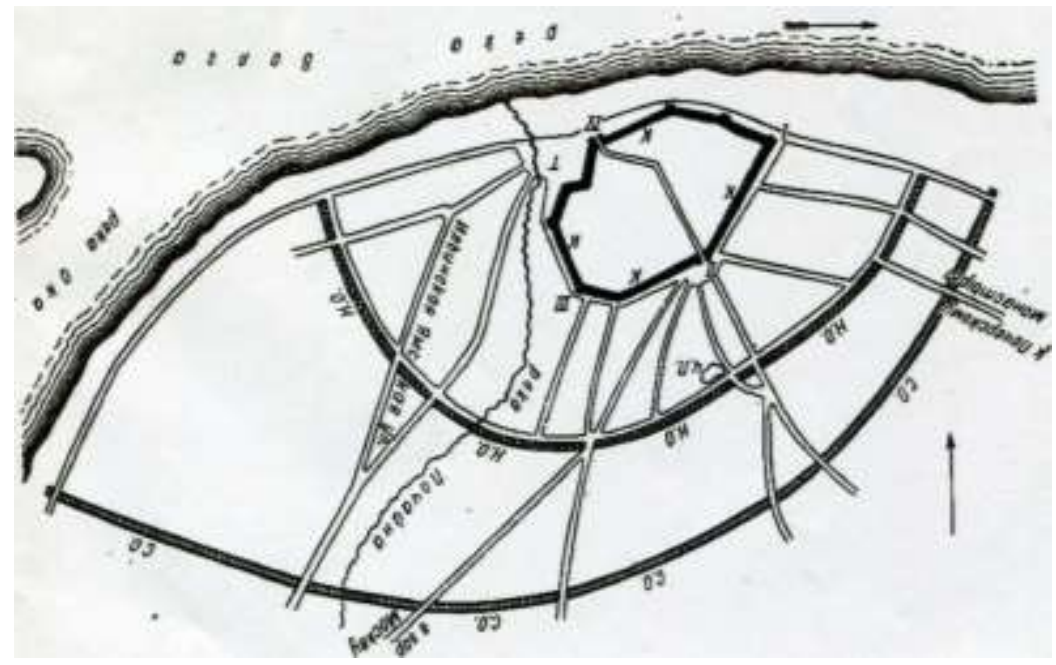

Fig. 8. Nizhny Novgorod. Ancient genetic parts, streets, and tracts in 17th c. in the formation of the urban development structure. The Kremlin: IEgor tower; II - the Dmitrovsky gate; III-Beam-tower; IV -Ivanovskie gates; T-Trade area of Nizhniy Posad; Ch. P-Black pond; K-the walls of the Kremlin; N.O-Old Posad; C. O.- New Posad.

A radial system was formed, consisting of 6 streets, that lead to the Dmitrov gate of the Kremlin, where the market square was also formed. Within the layout of the streets, the boundaries of the old and new posads were also reflected. A comparative analysis of the plan of Nizhny Novgorod from the beginning of the 20th century with the earlier plans confirms that the city followed a concentric principle of the development of the town planning structure ("Fig. 9"). The main trajectories were supported by composite nodes, such as The Holy Cross Monastery ("Fig. 10"). The main and the leading dominant of the vastly expanded territory, including the fairgrounds, was still the Kremlin, sitting on a steep hill as a symbol of the city.

As we see, the genetic code of Nizhny Novgorod began to form after the creation of the city and early construction ("Fig. 11") [16]. Its manifestation is confirmed by the following regularities:

- the influence of the planning of the Kremlin, of the 14th century on the configuration of the 
boundaries of the old and new prisons and the subsequent stages;

- the permanence of the dominant role of the Kremlin and the orientation of the main streets onto it;
- the continuation of the detachment of the genetically established parts (i.e. the upland part, Rozhdestvenskaya, etc.);

- the presence of the concentric principle in the formation of the town planning structure.

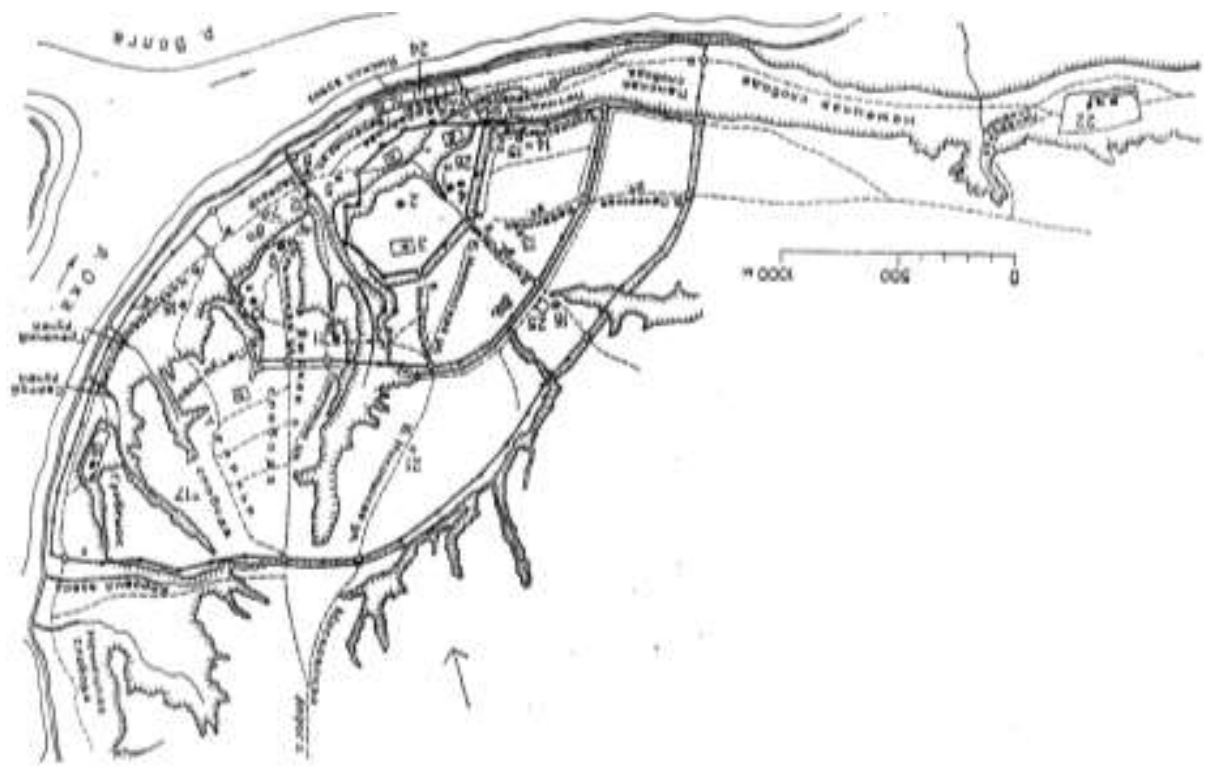

Fig. 9. Nizhny Novgorod as the center of the Volga region.

Reconstruction of the plan of the city of the 17th c. 1- Cathedral of the Transfiguration, 1652; 2- The Cathedral of the Archangel, 1631; 3- Church of the Resurrection, 1647; 4- the Church of Peter the Metropolitan; 5- Church of John the Baptist, 1683; 6- Church of St. Nicholas (na torgu), 1656; 7- Trinity Church, 1663; 8- Church of John the Divine; 9- Church of Elijah the Prophet, 1655; 10- Church of the Assumption, 1672; 11- Church of the Holy Myrrhbearing Women, 1649; 12- Kazan Church, 1678; 18- Church of the Nativity of the Virgin, 1653; 19Cathedral of the Annunciation, 1949; 20- Church of St. Paraskevi, 1689; 21 Church of the Intercession; the monasteries: 22- Pechersky, 1632- 1648; 23 of the Origin, 1614; monasterie of the metochion: 24 Troitse-Sergievskoe, Simonovskoe, Spaso-Evfimievskoe, Pokrovskoe; 25- Dudino; 26 - bishop's house, 1672

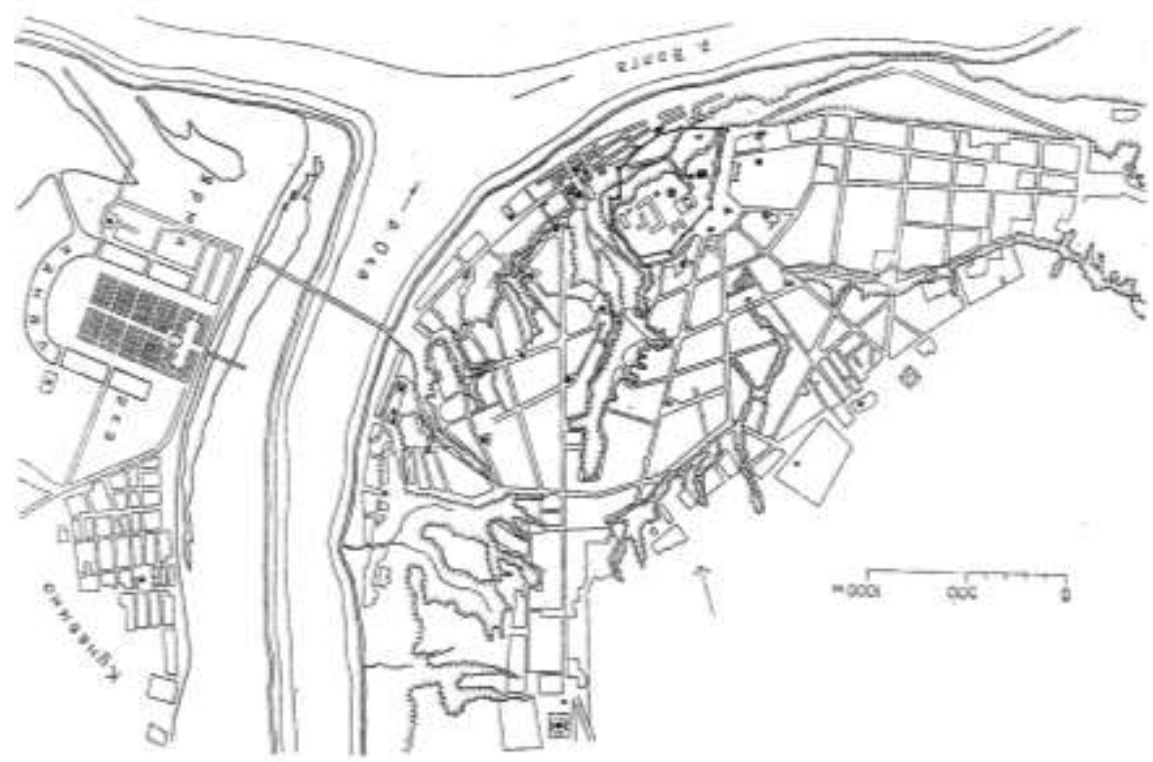

Fig. 10. Plan of Nizhny Novgorod of 1845, showing the All-Russian Exhibition Centre. 


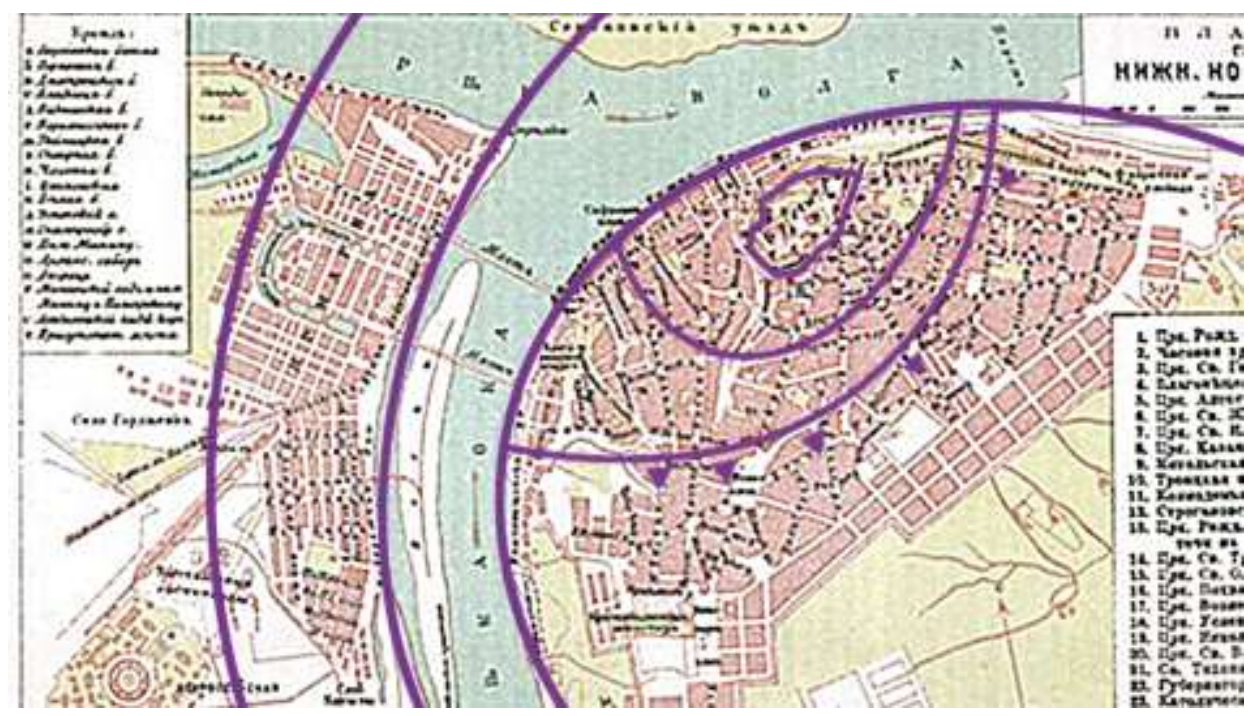

Fig. 11. Nizhny Novgorod. The concentric principle in the area growth.

\section{CONCluSion}

Graphical - analytical comparison of the historical boundaries of the city's territory, corresponding to the evolutionary stages, revealed the inner property of similarity of the form and configuration of the subsequent parts to the initial, ancient, and previously established ones. The pre-existent structure, as a model of different temporal layers, is characterized by stability, or permanence, the importance, and orientation towards dominant elements, preservation of the system-forming role of the crucial historical-genetic interconnections. Ancient planning parts form the basis of the zonal historical-genetic structure that in itself requires conservation.

\section{References}

[1] L.I. Kubeckaia, N.O. Kudryavtseva, "Historical-Genetic Regularities of Origin and Development of Urban Systems as an Integral Part of National Culture," Gradostroitelstvo (Urban Planning), no. 3, 2017, pp. 9-23 [in Russian].

[2] L.D. Mazur, Regularity of the Development of the Russian City of the 11th-18th Centuries: On the Example of Vladimir Province, the Dissertation for the Degree of Candidate of architecture. Moscow, 1998 [in Russian].

[3] Salat S., Bourdic L., "Sistemic Resilience of Complex Urban Systems on Trees and Leave," Journal of Land Use, Mobility, and Environment, Universita degli Studi di Napoli Federico 11, vol. 5, n. 2 August.

[4] Mokeev G.Y. (1971) Metropolitan Veche of Pskov, From the series "Monuments of Russian Culture" [in Russian].

[5] G.Y. Mokeev, "The Layout of the Ancient Russian Cities and the Method of Their Systems," Sources and Methods for Researching Monuments of Urban Planning and Architecture. ed. by A.V. Ryabushin. Moscow: Stroyizdat, 1980, pp. 7-17 [in Russian].

[6] N.G. Zarandia, "Protection and Use of Monuments of History and Culture in the District Planning (On the Example of
Mountain Regions of the Georgian SSR)", Town-Planning Problems of Protection and Use of Historical and Cultural Heritage, ed. by E.A. Pain \& S. K. Regame, 1989, pp. $56-75$ [in Russian].

[7] V. Gregotti, Architettura Postmetropol. Torino: Ginlio Eunaudi Editore, 2011.

[8] V.F. Marov, Yaroslavl: Architecture and Urban Planning. Yaroslavl: Upper Volga, 2000 [in Russian].

[9] L.I. Kubetskaia, "Heritage of the Yaroslavl Villages in Developing the Center (The Problem of Preserving the Identity of the Historical Settlements in the Modern Centre of the City of Yaroslavl)," Development of Historical City Centres, Conservation, Restoration and Use of Monuments, Materials of Scientific-Practical Conference: Collection of Scientific Works. Yaroslavl, 1984, pp. 53-62 [in Russian].

[10] S. Kostof, The City Assembled: The Elements of Urban Form Through History. Boston: Little Brown, 1992, p. 11.

[11] General History of Architecture, in 12 volumes, vol. 3, ed by A.V. Vlasov. Leningrad-Moscow: Construction and Architecture Publ., 1966, p. 599 [in Russian].

[12] S.I. Agafonov, Nizhny Novgorod Kremlin, Architecture, History, Restoration. Volga-Vyatka publishing house, 1976 [in Russian].

[13] S.I. Agafonov, Ibid.

[14] A.C. Shumilkin, Evolution of the Architectural and Planning Structure of the 18th-20th Centuries. The Abstract of the Dissertation for the Degree of Candidate of architecture. Nizhny Novgorod, 2010 [in Russian].

[15] A.C. Shumilkin, Ibid.

[16] A.C. Shumilkin, Ibid. 